\title{
Migraine treatment in developmental age: guidelines update
}

\author{
Laura Papetti • Alberto Spalice · Francesco Nicita • \\ Maria Chiara Paolino • Rosa Castaldo • \\ Paola Iannetti $\cdot$ Maria Pia Villa $\cdot$ Pasquale Parisi
}

Received: 5 January 2010/Accepted: 28 February 2010/Published online: 27 March 2010

(C) Springer-Verlag 2010

\begin{abstract}
There is a serious lack of controlled studies on the pharmacological treatment of primary migraine in the developmental age; there is, consequently, an urgent need for new, evidence-based approaches to this long-neglected field of research. Moreover, previous studies have stated that the placebo response is greater in pediatric patients than in adults and that a reduction in the attack frequency in the absence of any pharmacological treatment is observed more frequently in pediatric migraine patients than in adults. Besides these preliminary considerations, the shorter duration of migraine attacks and other characteristic semeiological features of the clinical picture in children are such that the design of randomized controlled trial (RCT) is more problematic in the developmental age than in the adult. Bearing in mind all these weak points, the aim of this review was to summarize and update recent guidelines for the treatment of primary migraine in children and adolescents. The most recent guidelines are those published by the Italian Society for the study of Headache, the French Society for the study of Migraine and Headache, and the American Academy of Neurology. We have incorporated into these guidelines the results from the few, recent RCTs, clinical controlled trials, open-label studies, meta-analyses and reviews that have been published since 2004; owing to the lack of strong evidence in this field of
\end{abstract}

L. Papetti · A. Spalice $\cdot$ F. Nicita $\cdot$ P. Iannetti

Child Neurology, Paediatric Department, I Faculty of Medicine,

Sapienza University, c/o Policlinico Umberto I, Rome, Italy

M. C. Paolino - R. Castaldo - M. P. Villa · P. Parisi ( $\square)$

Child Neurology, Headache Paediatric Center, Paediatric Sleep

Disorders Center, Chair of Paediatrics, II Faculty of Medicine,

Sapienza University, c/o Sant'Andrea Hospital,

Via di Grottarossa, 1035-1039 Rome, Italy

e-mail: pasquale.parisi@uniroma1.it; parpas@iol.it research, we have sometimes even mentioned pilot noncontrolled studies, case series and expert opinions. Lastly, evidence was classified and the recommendations were categorized according to different levels.

Keywords Pediatric migraine - Prophylaxis · Pharmacological treatment - Guidelines .

Evidence-based medicine - Acute treatment .

Migraine attack

\section{Introduction}

Migraine is a frequent condition in children, with a prevalence ranging from $3 \%$ in younger school-age children to approximately $20 \%$ in older adolescents [1].

The current classification system for primary migraine (Table 1) was published by the International Headache Society in 2004 and is known as the International Classification of Headache Disorders (ICHD-II) [2]. The ICHD-II for the diagnosis of pediatric migraine has been shown to have a sensitivity of $84 \%$ [3]. One of the limitations related to the use of ICHD-II criteria in the diagnosis of pediatric migraine is the difficulty children encounter in describing the features of headache and any associated symptoms. Moreover, as the features of headache may change from preschool age to adolescence [4], some authors have suggested modifying the criteria for headache diagnosis in childhood [5].

Despite the high frequency of migraine and the severity of attacks in the pediatric population, there is a serious lack of controlled data available in the literature on migraine therapy. Few randomized placebo-controlled trials on acute-phase or preventive drugs have yielded successful results in pediatric headache patients. Moreover, the high 
Table 1 International headache society classification of migraine (ICHD-II)

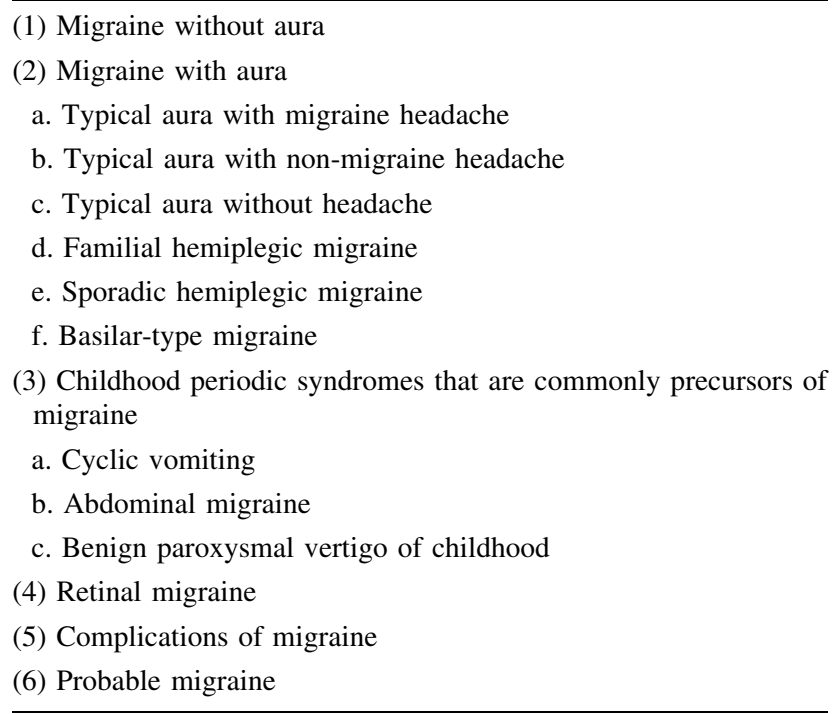

placebo response in some trials makes it difficult to prove the efficacy of the drug being studied [6].

The most recent practice guidelines for the therapy of pediatric migraine were published by the Italian Society for the study of Headache (SISC, 2003), the French Society for the study of Migraine and Headache (2004) and the American Academy of Neurology (AAN, 2004) [7-9]. The aims of this review were to update these guidelines [7-9], incorporating the results from randomized controlled trials (RCTs), clinical controlled trials (CCTs), open-label (OL) studies, meta-analyses and reviews published on this hot topic since 2004. Owing to the lack of strong evidence in this field of research, in certain cases we also mentioned pilot non-controlled studies, case series and expert opinions. Lastly, findings regarding pharmacological therapies were reviewed and the recommendations were categorized into different levels (A-C) (Table 2) [10].

\section{Literature search strategy}

In December 2009, an extensive search was undertaken to identify currently available headache treatment guidelines

Table 2 Levels of evidence for the treatment of migraine

Level A: two or more clinically controlled, randomized studies carried out according to good clinical practice (GCP), versus placebo or versus active treatment of proven efficacy

Level B: one clinically controlled, randomized study carried out according to GCP or more than one well-designed clinical casecontrol study or cohort study

Level C: favorable judgment of two-third of the Ad Hoc Committee members, historical controls, non-randomized studies, case reports (acute phase and prophylaxis). Moreover, we identified any RCTs, CCTs, OL studies, meta-analyses, reviews and articles that were either published or "in press" in the last 6 years (from 2004 to 2009) using the keywords "migraine and treatment or therapy" (293 papers), "migraine and prophylaxis" (66 papers) and "migraine and guidelines" (4 papers). Any relevant papers published in the same period that were not selected by these keywords were also taken into account. "PubMed" was used as the source for our search, which was not subjected to any language restriction, and any citations found in relevant studies were investigated. Our search was limited to the pediatric age group (0-18 years), although any articles that included adults but contained a high proportion of persons under the age of 18 years were considered. The only headache exclusion criteria adopted were the words "symptomatic or secondary". After the search and selection of the data was completed, two reviewers independently extracted the data, while a third reviewer solved any discrepancies.

The search identified 42 studies. One reviewer scanned these to eliminate any irrelevant studies. Three reviewers scanned the remaining 25 studies and the 30 relevant citations identified within these studies.

\section{Pediatric migraine treatment: general approach}

Appropriate treatment for children with migraine requires an individually tailored strategy, based on both pharmacological and non-pharmacological measures, defined according to the degree of disability caused by the headache [11]. The choice of therapy must be based on the symptoms, response to treatment and headache "impact", which reflects an individual patient's frequency, duration, intensity, functional disability, quality of life, comorbidity and pain tolerance [12].

The impact of migraine can be assessed in adults by using the migraine disability assessment (MIDAS) questionnaire [13]. However, since the MIDAS is not suitable for children because their lifestyles differ from those of adults, the pediatric migraine disability assessment (PedMIDAS) was developed. The range of the scoring system, which is based on the patient's disability, is wider than that of the MIDAS because children are more likely to omit activities. PedMIDAS can be used clinically to identify the impact of migraine in individual pediatric patients and assess their response to treatment [14].

The MIDAS questionnaire can also be used to stratify adult patients into groups with different treatment needs according to the degree of headache-related disability. Stratified care was developed as an alternative to the stepcare approach, which is instead preferred in the treatment of pediatric migraine, and places patients on non-specific 
medication that is gradually increased until effective relief is achieved [15].

The pharmacological treatment of pediatric migraine includes: acute or episodic medications and prophylactic or preventive agents [12].

\section{Acute treatments of migraine}

The aim of acute treatment should be a rapid response, resulting in a prompt return to normal activity and no relapse. To date, the only treatments that have been approved for migraine attacks in adolescents are almotriptan, by the US Food and Drugs Administration (FDA), and nasal sumatriptan and zolmitriptan, by the European Medicines Agency (EMEA) [19].

\section{Analgesics}

Ibuprofen is effective and should be considered for the acute treatment of migraine in children (Level A) [7-9].

Acetaminophen is probably effective and should be considered for the acute treatment of migraine in children (Level B) [7-9].

Ibuprofen $(10 \mathrm{mg} / \mathrm{kg})$ and acetaminophen $(15 \mathrm{mg} / \mathrm{kg})$ were more effective than placebo; the effect yielded by ibuprofen at $2 \mathrm{~h}$ was better than that of acetaminophen (68 vs. $54 \%$ of children relieved) and lasted longer. Neither drug had significant side effects $[11,17]$.

Recently Evers et al. [18] found that ibuprofen 200-400 mg was more effective than placebo in providing pain relief after $2 \mathrm{~h}$ ( $28 \%$ for placebo vs. $69 \%$ for ibuprofen; $P<0.05$ ).

The efficacy and safety of other non-steroid antiinflammatory drugs (NSAIDs) (e.g., acetylsalicylic acid, diclofenac, naproxen, mefenamic acid) in the treatment of migraine in children and adolescents have not yet been assessed [11].

\section{Triptans}

The family of triptans has improved the treatment of acute migraine in adults and several studies have demonstrated the safety of such drugs in children [1]. In 2009, the FDA approved almotriptan for the treatment of adolescent migraine, while nasal sumatriptan and zolmitriptan were approved for the acute treatment of adolescent migraine by the EMEA [19].

\section{Sumatriptan}

Sumatriptan nasal spray (NS) is effective and should be considered for the acute treatment of migraine in adolescents (Level A) [7-9].
Callenbach et al. [20] published a review of all controlled studies that evaluated the efficacy and safety of sumatriptan NS in the pediatric migraine population. Their review included seven trials, most of which included children aged 12-17 years as their study subjects. Intranasal sumatriptan was effective in relieving headache after both 1 and $2 \mathrm{~h}$ in all the studies, the response rates being comparable to those found in studies on adults. Four of the studies detected a significant difference in relief between sumatriptan and placebo (Table 3). Moreover, sumatriptan NS revealed a positive effect on vomiting and photophobia/ phonophobia. The main side effect was bad taste. Effective doses are $10 \mathrm{mg}$ for children weighing $<40 \mathrm{~kg}$ and $20 \mathrm{mg}$ for children weighing $>40 \mathrm{~kg}[11,17,21]$.

The most recent RCT was conducted by Winner et al. on 738 adolescent subjects (mean age 14 years) treated with sumatriptan NS (5 and $20 \mathrm{mg}$ ). Sumatriptan NS $20 \mathrm{mg}$ provided significantly greater headache relief than placebo at $30 \mathrm{~min}(42$ vs. $33 \%$, respectively; $P=0.046)$ and $2 \mathrm{~h}$ ( 68 vs. $58 \% ; P=0.025)$ post-dose, but did not reach statistical significance at either $1 \mathrm{~h}(61$ vs. $52 \% ; P=0.087)$ or for sustained headache relief from 1 to $24 \mathrm{~h}$ $(P=0.061)$. Significant differences $(P<0.05)$ in favor of sumatriptan NS $20 \mathrm{mg}$ over placebo were observed for several secondary efficacy endpoints, including sustained relief from 2 to $24 \mathrm{~h}$ [21].

No data are available to support or refute the use of any oral or subcutaneous sumatriptan preparations in children or adolescents (Level U) [7-9] because such preparations have yielded less positive data owing to their prominent side and placebo effects $[11,17]$.

\section{Zolmitriptan}

Studies in which oral zolmitriptan was compared with placebo have yielded contrasting results [11, 21, 22]. Since 2004, two large studies evaluating the efficacy and tolerability of oral zolmitriptan in pediatric migraine have been published [22, 23]. The first compared zolmitriptan at three different doses $(2.5,5$, and $10 \mathrm{mg})$ with placebo in 640 outpatients aged 12-17 years. Two-hour headache response rates were $54 \%(10 \mathrm{mg}), 53 \%(5 \mathrm{mg})$ and $57 \%(2.5 \mathrm{mg})$ for zolmitriptan, and $58 \%$ for placebo. Two-hour pain-free rates were $25 \%$ (10 mg), 19\% (5 mg), and $23 \%$ (2.5 mg) for zolmitriptan, and $20 \%$ for placebo. Zolmitriptan was well tolerated, with a tolerability profile similar to that observed in adults. The authors hypothesized that the similar efficacy observed in zolmitriptan and placebo may be the result of the high placebo response rate and the shorter duration of headache pain in adolescents if compared with adults [22].

Evers et al. conducted a double-blind, placebo-controlled, cross-over study in which patients received placebo, zolmitriptan $2.5 \mathrm{mg}$, and ibuprofen $200-400 \mathrm{mg}$, each being 
Table 3 Symptomatic drugs evaluated in placebo-controlled and open clinical trials

\begin{tabular}{|c|c|c|c|c|c|c|c|c|c|}
\hline Drug & $\begin{array}{l}\text { Evidence } \\
\text { level }\end{array}$ & $\begin{array}{l}\text { Study } \\
\text { design }\end{array}$ & $\begin{array}{l}\text { Ages } \\
\text { (years) }\end{array}$ & $n$ & $\begin{array}{l}\text { Primary end } \\
\text { point: } \\
\text { pain relief } \\
\text { (hours) }\end{array}$ & $\begin{array}{l}\text { Responders } \\
(\%)\end{array}$ & $\begin{array}{l}\text { Placebo } \\
\text { responses } \\
(\%)\end{array}$ & $P$ value & Author/Pubdate/Ref. \\
\hline \multicolumn{10}{|l|}{ Ibuprofen } \\
\hline $10 \mathrm{mg} / \mathrm{kg}$ & A & $\mathrm{rDBPC}$ & $4-16$ & 88 & 2 & 68 & 37 & $<0.05$ & $\begin{array}{l}\text { Hamalainen et al., } 1997 \text { [10 } \\
\text { 16] }\end{array}$ \\
\hline $7.5 \mathrm{mg} / \mathrm{kg}$ & & DBPC & $6-12$ & 84 & 2 & 76 & 53 & 0.006 & Lewis et al., $2002[10,16]$ \\
\hline $200-400 \mathrm{mg}$ & & DBPCCO & $6-18$ & 32 & 2 & 69 & 28 & $<0.05$ & Evers et al., 2006 [21] \\
\hline \multicolumn{10}{|l|}{ Acetaminophen } \\
\hline $15 \mathrm{mg} / \mathrm{kg}$ & $\mathrm{B}$ & $\mathrm{rDBPC}$ & $4-16$ & 88 & 2 & 54 & 37 & $<0.05$ & $\begin{array}{l}\text { Hamalainen et al., } 1997 \\
{[10,16]}\end{array}$ \\
\hline \multicolumn{10}{|c|}{ Sumatriptan nasal } \\
\hline $20 \mathrm{mg}$ & $\mathrm{A}$ & rDBPC & $6-10$ & 14 & 2 & 86 & 42.8 & 0.03 & Ueberall et al., 1999 [18] \\
\hline $5-10-20 \mathrm{mg}$ & & $\mathrm{rDBPC}$ & $12-17$ & 510 & 2 & $63-66$ & 53 & $<0.05$ & Winner et al., 2000 [18] \\
\hline $10-20 \mathrm{mg}$ & & rDBPCCO & $8-17$ & 83 & 2 & 64 & 39 & 0.003 & Ahonen et al., 2004 [18] \\
\hline $20 \mathrm{mg}$ & & $\mathrm{rDBPC}$ & $12-17$ & 738 & 1 & 61 & 52 & ns & Winner et al., 2006 [19] \\
\hline \multicolumn{10}{|l|}{ Sumatriptan oral } \\
\hline $50-100 \mathrm{mg}$ & $\mathrm{C}$ & $\mathrm{rDBPCCO}$ & $8-16$ & 23 & 2 & 30 & 22 & ns & $\begin{array}{l}\text { Hamalainen et al., } 1997 \\
{[10,16]}\end{array}$ \\
\hline \multicolumn{10}{|c|}{ Sumatriptan subcutaneous } \\
\hline $3-6 \mathrm{mg}$ & $\mathrm{C}$ & OL & $6-16$ & 17 & 2 & 64 & - & - & MacDonald, $1994[10,16]$ \\
\hline $0.06 \mathrm{mg} / \mathrm{kg}$ & & OL & $6-18$ & 50 & 2 & 78 & - & - & Linder, $1996[10,16]$ \\
\hline \multicolumn{10}{|l|}{ Zolmitriptan oral } \\
\hline $2.5-5 \mathrm{mg}$ & $\mathrm{C}$ & OL & $12-17$ & 38 & 2 & 88 & - & - & Linder et al., $2000[10,16]$ \\
\hline $2.5 \mathrm{mg}$ & & DBPCCO & $6-18$ & 32 & 2 & 62 & 28 & $P<0.05$ & Evers et al., 2006 [21] \\
\hline $2.5-5-10 \mathrm{mg}$ & & $\mathrm{rDBPC}$ & $12-17$ & 850 & 2 & $53-57$ & 58 & ns & Rothner et al., 2006 [20] \\
\hline \multicolumn{10}{|l|}{ Zolmitriptan NS } \\
\hline $5 \mathrm{mg}$ & $\mathrm{B}$ & SB-DBPC & $12-17$ & 171 & 1 & 58.1 & 43.3 & $P<0.05$ & Lewis et al., 2007 [22] \\
\hline \multicolumn{10}{|l|}{ Rizatriptan oral } \\
\hline $5 \mathrm{mg}$ & $\mathrm{C}$ & $\mathrm{rDBPC}$ & $12-17$ & 296 & 2 & 66 & 56 & ns & Winner et al., $2002[10,16$ \\
\hline $5 \mathrm{mg}$ & & $\mathrm{rDBPC}$ & $12-17$ & 234 & 2 & 68.2 & 68.8 & ns & Visser et al., 2004 [23] \\
\hline $5 \mathrm{mg}$ & & OL & $12-17$ & 686 & 2 & 77 & - & - & Visser et al., 2004 [23] \\
\hline $5-10 \mathrm{mg}$ & & $\mathrm{rDBPC}$ & $6-17$ & 96 & 2 & 74 & 36 & $P=0.001$ & Ahonen et al., 2006 [24] \\
\hline \multicolumn{10}{|l|}{ Almotriptan oral } \\
\hline $6.25-12.5 \mathrm{mg}$ & $\mathrm{B}$ & OL & $11-17$ & 15 & 2 & 85 & - & - & Charles et al., 2006 [25] \\
\hline $\begin{array}{l}6.25-12.5- \\
25 \mathrm{mg}\end{array}$ & & $\mathrm{rDBPC}$ & $12-17$ & 866 & 2 & $67-73$ & 55 & $P<0.001$ & Linder et al., 2008 [26] \\
\hline \multicolumn{10}{|l|}{ Eletriptan oral } \\
\hline $40 \mathrm{mg}$ & $\mathrm{C}$ & DBPC & $12-17$ & 267 & 2 & 57 & 57 & ns & Winner et al., 2007 [27] \\
\hline Naratriptan oral & $\mathrm{C}$ & DBPC & $12-17$ & 300 & 4 & $64-72$ & 65 & ns & Rothner et al., $1997[10,16$ \\
\hline
\end{tabular}

$\overline{D B P C}$ double-blind placebo-controlled, $D B P C C O$ double-blind placebo-controlled crossover, $r D B P C$ randomized double-blind placebo controlled, $H A$ headache, $O L$ open-label, $R R$ retrospective review

used to treat one of three consecutive migraine attacks. Pain relief rates after $2 \mathrm{~h}$ were $28 \%$ for placebo, $62 \%$ for zolmitriptan, and 69\% for ibuprofen (placebo vs. zolmitriptan $P<0.05$; placebo vs. ibuprofen $P<0.05$ ). Both drugs were well tolerated, only mild side effects being reported [23]. The 2-h headache response rates for zolmitriptan were similar to those observed in the previous study, while the placebo rate was lower. A possible reason for the low placebo rate might be that children and adolescents with severe migraine were enrolled in the second study. If compared with the other triptan trials in which the patients' characteristics were similar, the duration and frequency of attacks in the study by Evers et al. [23] were higher, resembling those observed in adulthood migraine. 
Lewis et al. conducted a novel, placebo-challenge study to evaluate the efficacy and tolerability of zolmitriptan NS in adolescent migraine. A total of 248 adolescents was studied in a randomized, double-blind, placebo-controlled, two-attack, cross-over trial with a single-blind placebo challenge. Seventy-seven patients responded to the placebo challenge and did not thus continue the study. Of the remaining 171 patients, zolmitriptan produced significantly higher headache response rates than placebo $1 \mathrm{~h}$ post-dose (58.1 vs. $43.3 \% ; P<0.02$ ), with an onset of action occurring as early as $15 \mathrm{~min}$. Zolmitriptan also produced a significant pain-free response at $1 \mathrm{~h}(27.7$ vs. $10.2 \%$ in the placebo group, $P<0.001$ ), proving to be significantly superior to placebo in improving pain intensity, pain-free rates, sustained resolution of headache and resolution of associated migraine symptoms. Treatment with zolmitriptan NS was well tolerated [24].

\section{Rizatriptan}

Two recent RCTs compared the efficacy of oral rizatriptan with placebo $[25,26]$.

Visser et al. evaluated the short- and long-term efficacy and tolerability of rizatriptan $5 \mathrm{mg}$ in adolescents with migraine. They conducted an rDBPC single-attack study followed by a randomized, 1-year, OL extension, as well as a randomized 1-year OL study. In the single-attack study, the proportion of patients in whom pain was relieved at $2 \mathrm{~h}$ was not significantly different in the rizatriptan $5 \mathrm{mg}$ $(68.2 \%)$ and placebo $(68.8 \%)$ groups. In the multiple attack studies, pain relief at $2 \mathrm{~h}$ was achieved in a significantly higher number of attacks treated with a rizatriptan 5-mg tablet $(77 \%)$ or with a rizatriptan 5-mg wafer $(77 \%)$ than by means of standard care (64\%). Rizatriptan $5 \mathrm{mg}$ was well tolerated in adolescents during both short- and longterm use [25].

The second study investigated the efficacy of oral rizatriptan $(5$ and $10 \mathrm{mg}$ ) and the consistency of the response over two treated migraine attacks in children and adolescents over 6 years of age. Two doses of rizatriptan and a matching placebo were administered at home during three attacks. Headache relief at $2 \mathrm{~h}$ was achieved twice as often after each rizatriptan treatment (first $74 \%$; second $73 \%$ ) as after placebo $(36 \%)(P=0.001)$. The efficacy of rizatriptan was constant over the two treated attacks, while the findings were similar regardless of the dose administered ( 5 and $10 \mathrm{mg}$ ). No serious adverse effects were observed. The efficacy and the tolerance of rizatriptan in children below 12 years of age did not differ from those observed in adolescents [26].

\section{Almotriptan}

Two studies investigated the efficacy and safety of almotriptan in adolescents with migraine [27, 28].

The first is a small OL placebo-controlled trial. Fifteen patients aged 11-17 years with a history of migraine were treated with almotriptan at doses ranging from 6.25 to $12.5 \mathrm{mg}$. Almotriptan was effective in 13 patients, with no significant adverse effects being reported [27].

The FDA approval of almotriptan for the acute treatment of migraine headache in adolescents was based on data from a recent randomized placebo-controlled trial. Linder et al. assessed the efficacy and safety of almotriptan 6.25, 12.5, and $25 \mathrm{mg}$ versus placebo for acute migraine treatment in adolescents (866 patients aged 12-17 years). The 2-h painrelief rates were significantly higher with almotriptan $6.25 \mathrm{mg}$ (71.8\%), $12.5 \mathrm{mg}$ (72.9\%), and $25 \mathrm{mg}$ (66.7\%) than with placebo $(55.3 \% ; P=0.001, P<0.001$ and $P=0.028$, respectively). Age group sub-analysis demonstrated significantly greater 2 -h pain-relief rates for patients aged 15-17 years, a significantly lower incidence of photophobia and phonophobia $2 \mathrm{~h}$ after almotriptan $12.5 \mathrm{mg}$ administration in patients aged 15-17 years than in the placebo group, and a significantly lower incidence of photophobia following almotriptan $12.5 \mathrm{mg}$ administration in patients aged 12-14 years than in the placebo group [28].

\section{Eletriptan}

A multicenter, double-blind, parallel-group, placebo-controlled trial compared $40 \mathrm{mg}$ of oral eletriptan with placebo for the treatment of migraine in adolescent patients aged 12-17 years. Drug efficacy was evaluated in patients $2 \mathrm{~h}$ post-dose. There was no significant difference in the $2 \mathrm{~h}$ headache response between eletriptan $40 \mathrm{mg}$ and placebo (57 vs. $57 \%$ ), nor was any significant improvement observed in any of the outcomes 1 or $2 \mathrm{~h}$ post-dose. By contrast, eletriptan $40 \mathrm{mg}$ proved to be significantly more effective in reducing headache recurrence than placebo within $24 \mathrm{~h}$ (11 vs. $25 \%, P=0.028$ ), with post hoc analyses showing statistically significant differences for sustained headache response rates (52 vs. $39 \% ; P=0.04$ ) and sustained painfree response rates (22 vs. $10 \% ; P=0.013$ ) [29].

\section{Antiemetics}

There is one recent randomized-controlled study on pediatric migraine therapy in the emergency room that compared the efficacy of prochlorperazine with that of ketorolac. In that study, prochlorperazine was found to be 
more effective than ketorolac as regards the primary outcome, which was a decrease in the intensity of the migraine by $50 \%$ or complete relief within $1 \mathrm{~h}$ : $28 / 33(85 \%)$ versus $16 / 29$ (55\%), respectively [30].

The drugs and acute-phase treatment outcome in pediatric migraine patients are shown in Table 3 .

\section{Prophylactic treatment of pediatric migraine}

Prophylactic pharmacological treatment may be considered when headache frequency exceeds three or four episodes per month and/or the attacks are so severe and prolonged that they interfere with school or normal activities. The goals of prophylactic therapy include: reducing attack frequency, severity and duration, improving responsiveness to treatment of acute attacks, improving function and quality of life, and reducing disability [31].

\section{Calcium channel blockers}

\section{Flunarizine}

The Italian, French and AAN practice parameters on the management of pediatric migraine (2004) and the Cochrane review (2003) suggest that the calcium channel blocker, flunarizine, is likely to be effective as preventive therapy and may be considered for this purpose (Level b) $[9,32]$.

Although it is not available in the United States, flunarizine has yielded good results in several controlled trials and has a proven efficacy ( $5 \mathrm{mg}$ bedtime dose) in reducing headache frequency and headache duration. The main side effects are daytime sedation and weight gain $[10,33]$.

\section{Antidepressants}

\section{Amitriptyline}

Although the efficacy of amitriptyline in pediatric migraine has never been assessed in RCTs, it remains one of the most widely used agents. Starting doses of 5-10 mg at bedtime may gradually be increased to $1 \mathrm{mg} /(\mathrm{kg}$ day $)$. Cardiac abnormalities and depression represent a contraindication for the use of this drug $[1,11,31]$.

\section{Antiepileptic drugs}

Topiramate, valproate, levetiracetam and gabapentin may play increasingly important roles in pediatric migraine. In the light of current views on the pathophysiology of migraine, particularly as regards the primary neuronal initiation and propagation through cortical excitation, and subsequent "spreading depression," anticonvulsants may play an intriguing, though not yet fully defined, role [33].

\section{Topiramate}

Recent studies have shown that topiramate is effective in reducing headache frequency and disability in adolescents (Table 4) [34-39].

Since 2004, three double-blind placebo controlled trials [34-37], one pooled analysis of RCTs [38] and one retrospective review have been published [39].

Winner et al. [35] conducted a placebo-controlled trial in 157 children with migraine aged from 6 to 15 years who were randomized in a 2:1 ratio to receive either topiramate [2 $\mathrm{mg} /(\mathrm{kg}$ day)] or placebo. The primary outcome was the change in the mean number of migraine days per month. Topiramate treatment was associated with a mean reduction of 2.6 migraine days per month as compared with 2.0 in the placebo group. The difference between the two groups marginally missed the significance level $(P=0.06)$. Response to topiramate (i.e., $>50 \%$ reduction in migraine frequency) was 55 versus $47 \%$ in the placebo group. The most common adverse effects were upper respiration tract infection, anorexia, weight decrease, gastroenteritis, paresthesia and somnolence [35].

Winner et al. [38] performed a second study in which data from subjects aged 12-17 years who had participated in three previous RCTs with a similar design were pooled. All three previous studies had compared topiramate at a dose of 100 or $200 \mathrm{mg} /$ day with placebo. The primary outcome measure was the median percentage reduction in the monthly migraine frequency. Topiramate at a dose of 100 and $200 \mathrm{mg} /$ day was associated with a statistically significant reduction in migraine frequency when compared with placebo (respectively 63 and 65 vs. $16 \%$ for placebo, $P=0.02$ for topiramate $100 \mathrm{mg} /$ day and $P=0.04$ for topiramate $200 \mathrm{mg} / \mathrm{day}$ ). Topiramate at a dose of $50 \mathrm{mg} /$ day was less effective (46\% reduction, $P=0.07)$ [38].

Lewis et al. evaluated the efficacy and safety of topiramate (50 or $100 \mathrm{mg} /$ day) for migraine prevention in 85 adolescents (12-17 years of age). The primary efficacy measure was the reduction in the number of monthly migraine attacks. Topiramate at a dose of $100 \mathrm{mg} /$ day, though not $50 \mathrm{mg} / \mathrm{day}$, resulted in a statistically significant reduction in the monthly migraine attack rate if compared with the placebo group (median 72.2 vs. $44.4 \%$ ). Topiramate at a dose of $100 \mathrm{mg} /$ day also resulted in a statistically significant reduction in the number of monthly migraine days if compared with the placebo group ( 83 vs. $45 \%$ for placebo) [37].

A third double-blind placebo-controlled trial was conducted in 44 children with migraine. Twenty-two patients 
Table 4 continued

\begin{tabular}{|c|c|c|c|c|c|c|c|c|}
\hline Drug & $\begin{array}{l}\text { Evidence } \\
\text { level }\end{array}$ & $\begin{array}{l}\text { Study } \\
\text { design }\end{array}$ & $\begin{array}{l}\text { Ages } \\
\text { (years) }\end{array}$ & $n$ & $\begin{array}{l}\text { Drug } \\
\text { response } \\
\text { rate }(\%)\end{array}$ & $\begin{array}{l}\text { Placebo } \\
\text { response } \\
\text { rate }(\%)\end{array}$ & $\begin{array}{l}P \text { value (primary } \\
\text { endpoint) }\end{array}$ & Reference \\
\hline \multicolumn{9}{|l|}{ Flunarizine } \\
\hline $5 \mathrm{mg}$ & A & DBPC & $7-14$ & 42 & 76 & 19 & $\begin{array}{l}P<0.001 \\
\quad(\text { freq and durat) }\end{array}$ & Sorge et al., $1985[1,10]$ \\
\hline $5 \mathrm{mg}$ & & OL & $10-13$ & 12 & 66 & - & - & Guidetti et al., $1987[1,10]$ \\
\hline $5 \mathrm{mg}$ & & $\begin{array}{l}\text { DBPC } \\
\mathrm{CO}\end{array}$ & $5-11$ & 63 & 67 & 33 & $\begin{array}{l}P<0.001 \text { (freq) } \\
P<0.01 \text { (durat) }\end{array}$ & Sorge et al., $1988[1,10]$ \\
\hline \multicolumn{9}{|l|}{ Nimodipine } \\
\hline $10-20 \mathrm{mg}$ & $\mathrm{C}$ & DBPCCO & $7-18$ & 37 & 15 & 15 & ns (freq) & Battistella et al., $1990[1,10]$ \\
\hline \multicolumn{9}{|l|}{ Propanolol } \\
\hline $60-120 \mathrm{mg}$ & $\mathrm{C}$ & $\mathrm{DBCO}$ & $7-16$ & 28 & 82 & 14 & $P<0.001$ (freq) & $\begin{array}{l}\text { Ludvigsson et al., } 1974 \\
{[1,10]}\end{array}$ \\
\hline $80 \mathrm{mg}$ & & DBPC & $3-12$ & 39 & 58 & 55 & $\mathrm{~ns}$ & Forsythe et al. $1984[1,10]$ \\
\hline $3 \mathrm{mg} / \mathrm{kg}$ & & DBPC & $6-12$ & 28 & ns & ns & ns & Olness et al., $1987[1,10]$ \\
\hline Timolol & $\mathrm{C}$ & $\begin{array}{l}\text { DBPC } \\
\text { CO }\end{array}$ & $6-13$ & 19 & 38 & 40 & $\mathrm{~ns}$ & Noronha et al. $1985[1,10]$ \\
\hline \multicolumn{9}{|l|}{ Clonidine } \\
\hline $25-50 \mu \mathrm{g}$ & $\mathrm{C}$ & DBPC & $<15$ & 57 & 32 & 34 & ns & Sillanpaa, $1977[1,10]$ \\
\hline $0.07-0.1 \mathrm{mg}$ & & DBPC & $7-14$ & 43 & $\mathrm{~ns}$ & ns & ns & Sills et al., $1982[1,10]$ \\
\hline \multicolumn{9}{|l|}{ Cyproheptadine } \\
\hline $4 \mathrm{mg}$ & $\mathrm{C}$ & $\mathrm{RR}$ & $3-12$ & 30 & 83 & - & - & Lewis et al., 2004 [32] \\
\hline \multicolumn{9}{|l|}{ Amitriptyline } \\
\hline $1 \mathrm{mg} / \mathrm{kg}$ & $\mathrm{C}$ & OL & $9-15$ & 192 & 84 & - & - & Hershey et al., $2000[1,10]$ \\
\hline $10 \mathrm{mg}$ & & $\mathrm{RR}$ & $3-18$ & 73 & 89 & - & - & Lewis et al., 2004 [32] \\
\hline \multicolumn{9}{|l|}{ Trazodone } \\
\hline $1 \mathrm{mg} /(\mathrm{kg}$ day $)$ & $\mathrm{C}$ & DBPC & $7-18$ & 35 & 45 & 40 & ns & Battistella et al., $1993[1,10]$ \\
\hline Pizotifen & $\mathrm{C}$ & $\begin{array}{l}\text { DBPC } \\
\text { CO }\end{array}$ & $7-14$ & 47 & 15 & 16 & $\mathrm{~ns}$ & Gilles et al., $1986[1,10]$ \\
\hline \multicolumn{9}{|l|}{ Topiramate } \\
\hline $12.5-225 \mathrm{mg}$ & A & OL & $8-15$ & 75 & $43-59$ & - & $P<0.001$ (freq) & Hershey et al., $2002[1,10]$ \\
\hline $2-3 \mathrm{mg} / \mathrm{kg}$ & & $\mathrm{rDBPC}$ & $6-15$ & 162 & 54.6 & 46.9 & ns & Winner et al., 2005 [35] \\
\hline $50,100,200 \mathrm{mg}$ & & DBPC & $12-17$ & 51 & $46-65$ & 16 & $\begin{array}{l}P=0.02(100 \mathrm{mg}) \\
P=0.04(200 \mathrm{mg}) \\
\quad(\text { freq })\end{array}$ & Winner et al., 2006 [38] \\
\hline $100 \mathrm{mg}$ & & DBPC & $8-14$ & 44 & 95 & 52 & $P=0.02($ freq $)$ & Lakshmi et al., 2007 [36] \\
\hline $100 \mathrm{mg}$ & & $\mathrm{rDBPC}$ & $12-17$ & 85 & 83 & 45 & $P<0.001$ (freq) & Lewis et al., 2009 [37] \\
\hline 50-200 mg & & $\mathrm{RR}$ & $7-20$ & 37 & 76 & - & $P<0.001$ (freq) & Cruz et al., 2009 [39] \\
\hline \multicolumn{9}{|l|}{ Valproate } \\
\hline $\begin{array}{l}15-45 \mathrm{mg} / \\
\text { (kg day) }\end{array}$ & B & OL & $7-16$ & 42 & 78.5 & - & $P<0.05$ (freq) & Caruso et al., $2000[1,10]$ \\
\hline $\begin{array}{l}500-1,000 \mathrm{mg} / \\
\text { day }\end{array}$ & & OL & $9-17$ & 10 & 83 & - & $P=0.002($ freq $)$ & Serdaroglu et al., $2002[1,10]$ \\
\hline $\begin{array}{l}250-1,125 \mathrm{mg} / \\
\text { day }\end{array}$ & & $\mathrm{OL}$ & $7-17$ & 23 & 65 & - & $P<0.05$ (freq) & Pekalnis et al., $2001[1,10]$ \\
\hline $\begin{array}{l}10-40 \mathrm{mg} / \\
\text { (kg day) }\end{array}$ & & rDBPC & $3-15$ & 58 & 72 & - & $P<0.05$ (freq) & Ashrafi et al., 2005 [40] \\
\hline $\begin{array}{l}250,500 \\
1,000 \mathrm{mg}\end{array}$ & & rDBPC & $12-17$ & 300 & $36-51$ & 46 & ns & Apostol et al., 2008 [41] \\
\hline $500-1,000 \mathrm{mg}$ & & OL & $12-17$ & 241 & - & - & $>75 \%$ (freq) & Apostol et al., 2009 [42] \\
\hline Levetiracetam & $\mathrm{B}$ & OL & 19 & $3-17$ & 52 & - & $P<0.001$ (freq) & Miller et al., $2004[1,10]$ \\
\hline $250-1,500 \mathrm{mg}$ & & OL & 20 & $6-17$ & 90 & - & $P<0.001$ (freq) & Pekalnis et al., 2007 [44] \\
\hline
\end{tabular}


Table 4 Prophylactic drugs evaluated in placebo-controlled and open clinical trials

\begin{tabular}{lllllllll}
\hline Drug & $\begin{array}{l}\text { Evidence } \\
\text { level }\end{array}$ & $\begin{array}{l}\text { Study } \\
\text { design }\end{array}$ & $\begin{array}{l}\text { Ages } \\
\text { (years) }\end{array}$ & $n$ & $\begin{array}{l}\text { Drug response } \\
\text { rate }(\%)\end{array}$ & $\begin{array}{l}\text { Placebo } \\
\text { response } \\
\text { rate (\%) }\end{array}$ & $\begin{array}{l}P \text { value (primary } \\
\text { endpoint) }\end{array}$ & Reference \\
\hline $\begin{array}{r}\text { Gabapentin } \\
15 \mathrm{mg} / \mathrm{kg}\end{array}$ & $\mathrm{C}$ & $\mathrm{RR}$ & 18 & $6-17$ & 83 & - & $P<0.001$ (freq) & Belman et al., 2001 [1, 10] \\
$\begin{array}{r}\text { Zonisamide } \\
5.8 \mathrm{mg} / \mathrm{kg}\end{array}$ & $\mathrm{C}$ & $\mathrm{OL}$ & 12 & $10-17$ & 66 & - & - & Pakalnis et al., 2006 [45] \\
\hline
\end{tabular}

$D B P C$ double-blind placebo-controlled, $D B P C C O$ double-blind placebo-controlled crossover, $r D B P C$ randomized double-blind placebo controlled, $O L$ open-label, $R R$ retrospective review, freq attack frequency, durat. attack duration

received topiramate (final dose of $100 \mathrm{mg}$ ) while 22 received placebos. There was a statistically significant decrease in the mean monthly migraine frequency in the topiramate group as compared with the placebo group (11.9 vs. 5.9 days, $P=0.025$ ). Ninety-five percent of the subjects in the topiramate group were classified as responders (i.e., $>50 \%$ reduction in migraine frequency) as compared with $52 \%$ in the placebo group $(P=0.002)$. Moreover, topiramate was associated with a lower degree of functional disability than placebo. The authors reported a statistically significant difference between the two groups in both the decrease in the PedMIDAS score $(P=0.003)$ and in school absenteeism $(P=0.002)$ [36].

Cruz et al. retrospectively reviewed the records of 37 patients (mean age 14 years) with migraine. An excellent or good response (i.e., $>50 \%$ migraine reduction) with topiramate was attained in 28 patients $(76 \%)$. Ten $(27 \%)$ patients exhibited adverse effects [39].

\section{Valproic acid}

Open-label and retrospective studies $[1,10]$ have suggested that valproic acid may be effective in the prevention of migraine in children and adolescents.

Ashrafi et al. compared the effect of sodium valproate $[10-40 \mathrm{mg} /(\mathrm{kg}$ day $)]$ in pediatric migraine prophylaxis with that of propranolol in an RCT that included 120 children. Both drugs significantly reduced the mean migraine frequency if compared with the pre-randomization period by 5.1 migraine days/month. Response (i.e., $>50 \%$ reduction in migraine frequency) was observed in $72 \%$ of the valproate group and in $69 \%$ of the propranolol group. Furthermore, both drugs were found to effectively reduce the severity and duration of headache and to improve the response to rescue medications ( $P$ value $<0.01$ ). There was no significant difference between the two groups in any of the aforementioned therapeutic effects $(P$ value $<0.05)[40]$.

To compare the efficacy, tolerability and safety of three different doses of divalproex sodium extended-release (DVPX ER) with placebo, Apostol et al. conducted a randomized double-blind placebo-controlled trial. The study included 299 adolescents aged 12-17 years. The participants were randomized in a 1:1:1:1 ratio to receive DVPX ER 250, 500, or 1,000 mg once daily or placebo. The median reduction in the migraine rate was slight and similar in all four groups in the study (1.7 migraine days in the placebo, 250 and 1,000 $\mathrm{mg}$ divalproex groups, and 1.4 in the $500 \mathrm{mg}$ group). Response (i.e., $>50 \%$ reduction in migraine frequency) was $46 \%$ in the placebo group as compared with 41, 36 and 51\% in the DVPX ER $250 \mathrm{mg}$, 500 or $1,000 \mathrm{mg}$ groups, respectively. DVPX ER was not superior to placebo in the migraine-related quality of life measures either, as assessed by the PedMIDAS [41].

A fourth OL study was conducted on 241 adolescents aged 12-17 years with migraine. The DVPX ER dose range was $250-1,000 \mathrm{mg}$ daily. Efficacy was based on the number of migraine headache days reported in the subjects' headache diaries over sequential 4-week periods for the duration of the trial. DVPX ER treatment was associated with a $75 \%$ decrease (from 4.0 to 1.0 ) in the median number of headache days over a 4 -week period between the first and the fourth months of the study [42].

\section{Levetiracetam}

Since 2004, two OL studies have been conducted to evaluate the efficacy and safety of levetiracetam in pediatric migraine $[43,44]$. The first study is a retrospective study in which levetiracetam was assessed in 19 patients (mean age 12 years) at doses of $125-250 \mathrm{mg}$ t.i.d. The mean frequency of headache attacks, which was 6.3/month before treatment, fell to $1.7 /$ month after treatment $(P<0.0001)$. The migraine attacks disappeared in $52 \%$ of the patients during the treatment, though $10.5 \%$ discontinued the treatment owing to side effects [43].

The second OL study included 20 pediatric patients (617 years). Levetiracetam dosages ranged from 20 to $40 \mathrm{mg} /(\mathrm{kg}$ day). The primary outcome measure was response (i.e., $\geq 50 \%$ reduction in monthly headache frequency). Eighteen of the 20 patients responded positively to levetiracetam, with a reduction of over $50 \%$ reduction in 
the monthly headache frequency ( $90 \%$ response rate) and a significant difference after treatment. The PedMIDAS revealed a significant decrease in the disability scores following levetiracetam treatment. The drug was well tolerated by the participants; the only adverse effects reported being irritability, aggressiveness and mild memory problems $(15 \%)$ [44].

\section{Zonisamide}

A retrospective chart review was conducted to study the efficacy of zonisamide in pediatric migraine prophylaxis. Twelve patients were identified (mean age 13.5 years). Eight patients responded positively to zonisamide, with a reduction of over 50\% in the number of headaches if compared with the pretreatment values. Zonisamide was well tolerated, with only two patients reporting adverse effects that consisted in weight loss and behavioral changes [45].

According to our search, no RCTs, CCTs or OL studies designed to assess the efficacy and safety of antidepressants (amitriptyline and trazodone), b-blockers (propranolol and timolol) and other antihypertensive agents, such as clonidine, have been conducted on adolescent and childhood migraine since 2004 (Table 4).

The evidence levels of all the aforementioned prophylactic drugs are shown in Table 4.

\section{Conclusions}

Few advances have been made in the treatment of pediatric migraine since 2004. As regards the acute phase treatment, prospects are unfortunately not very promising; the only drugs that are effective and safe in children being ibuprofen (Level A), acetaminophen (Level B), and sumatriptan NS (Level A). Zolmitriptan NS, which has recently been investigated, proved to be more effective than placebo (Level B). Almotriptan was approved by the FDA for the acute treatment of adolescent migraine even more recently (Table 3).

As regards prophylactic treatment, topiramate has recently displayed a good level of efficacy, safety and tolerance (Level A), while flunarizine (Level A) and valproate (Level B) were already included in the previously published guidelines [7-9].

Further researches are warranted to shed more light on the underlying mechanisms of migraine and provide new treatment options designed to raise the efficacy and safety levels of currently available drugs. Moreover, additional RCTs and more controlled data are needed to help clinicians choose the most appropriate drugs for the treatment of this common clinical problem. In this regard, new and innovative study designs are required to minimize the high placebo response observed in the pediatric population.

Acknowledgments This Tutorial partly results from the lesson of the Author (PP) at the Master in Headache Medicine, Sapienza University of Rome, during the academic year 2009-2010 (http://w3. uniroma1.it/headache). This Academic Educational activity is done under the supervision of Lifting The Burden-WHO Global Campaign against Headache-Working Group for Specialist Education (SEWG) (http://www.who.int/mental_health/neurology/headache/en/; http://www.l-t-b.org).

Conflict of interest None.

\section{References}

1. Lewis D (2009) Pediatric migraine. Neurol Clin 27:481-501

2. Olesen J, Steiner TJ (2004) The international classification of headache disorders. Cephalalgia 24:1-160

3. Hershey AD, Winner P, Kabbouche MA et al (2005) Use of the ICHD-II criteria in the diagnosis of pediatric migraine. Headache 45:1288-1297

4. Pakalnis A (2007) Current therapies in childhood and adolescent migraine. J Child Neurol 22:1288-1292

5. Winner P (2008) Pediatric headache. Curr Opin Neurol 21:316-322

6. Evers S, Marziniak M, Frese A et al (2009) Placebo efficacy in childhood and adolescence migraine: an analysis of double-blind and placebo-controlled studies. Cephalalgia 29(4):436-444

7. Società Italiana per lo Studio delle Cefalee (SISC) (2003) Linee guida per la diagnosi e per la terapia della cefalea giovanile. Anno V-S1

8. Géraud G, Lantéri-Minet M, Lucas C et al (2004) French guidelines for the diagnosis and management of migraine in adults and children. French Society for the Study of Migraine Headache (SFEMC). Clin Ther 26(8):1305-1318

9. Lewis D, Ashwal S, Hershey A et al (2004) Practice parameter: pharmacological treatment of migraine headache in children and adolescence. Neurology 63:2215-2224

10. "Ad Hoc Committee" (2001) Diagnostic, therapeutic guidelines for migraine, cluster headache. J Headache Pain 2(3):105-192

11. Balottin U, Termine C (2007) Recommendations for the management of migraine in paediatric patients. Expert Opin Pharmacother 8(6):731-744

12. Gunner KB, Smith HD, Ferguson LE (2008) Practice guideline for diagnosis and management of migraine headaches in children and adolescents: part two. J Pediatr Health Care 22(1):52-59

13. Edmeads J, Láinez JM, Brandes JL et al (2001) Potential of the migraine disability assessment (MIDAS) questionnaire as a public health initiative and in clinical practice. Neurology $56(6$ Suppl 1):S29-S34

14. Hershey AD, Powers SW, Vockell AL et al (2001) PedMIDAS: development of a questionnaire to assess disability of migraines in children. Neurology 57(11):2034-2039

15. Lipton RB, Silberstein SD (2001) The role of headache-related disability in migraine management: implications for headache treatment guidelines. Neurology 56(6 Suppl 1):S35-S42

16. Lewis DW, Winner P (2006) The pharmacological treatment options for pediatric migraine: an evidence-based appraisal. NeuroRx 3(2):181-191

17. Silver S, Gano D, Gerretsen P (2008) Acute treatment of paediatric migraine: a meta-analysis of efficacy. J Paediatr Child Health 44(1-2):3-9 
18. Evers S, Rahmann A, Kraemer C et al (2006) Treatment of childhood migraine attacks with oral zolmitriptan and ibuprofen. Neurology 67(3):497-499

19. Hershey AD (2010) Current approaches to the diagnosis and management of pediatric migraine. Lancet Neurol 9:190-204

20. Callenbach PM, Pels LP, Mulder PG et al (2007) Sumatriptan nasal spray in the acute treatment of migraine in adolescents and children. Eur J Paediatr Neurol 11(6):325-330

21. Winner P, Rothner AD, Wooten JD (2006) Sumatriptan nasal spray in adolescent migraineurs: a randomized, double-blind, placebo-controlled, acute study. Headache 46(2):195-196

22. Rothner AD, Wasiewski W, Winner P et al (2006) Zolmitriptan oral tablet in migraine treatment: high placebo response in adolescents. Headache 46:101-109

23. Evers S, Rahmann A, Kraemer C et al (2006) Treatment of childhood migraine attacks with oral zolmitriptan and ibuprofen. Neurology 67:497-499

24. Lewis DW, Winner P, Hershey AD et al (2007) Adolescent migraine steering committee. Efficacy of zolmitriptan nasal spray in adolescent migraine. Pediatrics 120:390-396

25. Visser WH, Winner P, Strohmaier K et al (2004) Rizatriptan $5 \mathrm{mg}$ for the acute treatment of migraine in adolescents: results from a double-blind, single-attack study and two open-label, multiple-attack studies. Headache 44(9):891-899

26. Ahonen K, Hamalainem ML, Eerola M (2006) A randomized trial of rizatriptan in migraine attacks in children. Neurology 67:20052014

27. Charles JA (2006) Almotriptan in the acute treatment of migraine in patients 11-17 years old: an open-label pilot study of efficacy and safety. J Headache Pain 7(2):95-97

28. Linder SL, Mathew NT, Cady RK et al (2008) Efficacy and tolerability of almotriptan in adolescents: a randomized, doubleblind, placebo controlled trial. Headache 48(9):1326-1336

29. Winner P, Linder S, Lipton RB et al (2007) Eletriptan for the acute treatment of migraine in adolescents: results of a doubleblind, placebo-controlled trial. Headache 47(4):511-518

30. Brousseau DC, Duffy SJ, Anderson AC, Linakis JG (2004) Treatment of pediatric migraine headaches: a randomized, double-blind trial of prochlorperazine versus ketorolac. Ann Emerg Med 43:256-262

31. Eiland LS, Jekins LS, Durham SH et al (2007) Pediatric migraine: pharmacologic agents for prophylaxis. Pediatrics 41:1181-1190
32. Lewis D, Diamond S, Scott D (2004) Prophylactic treatment of pediatric migraine. Headache 44:230-237

33. Parisi P (2009) Who's still afraid of the link between headache and epilepsy? Some reactions to and reflections on the article by Marte Helene Bjørk and co-workers. J Headache Pain 10(5):327-329

34. Cuvellier JC, Riquet A, Vallée L (2008) Antiepileptic drugs in pediatric migraine. Arch Pediatr 15(11):1693-1699

35. Winner P, Pearlman EM, Linder SL et al (2005) Topiramate pediatric migraine study investigators. Topiramate for migraine prevention in children: a randomized, double-blind, placebocontrolled trial. Headache 45:1304-1312

36. Lakshmi CV, Singhi P, Malhi P et al (2007) Topiramate in the prophylaxis of pediatric migraine: a double-blind placebo-controlled trial. Child Neurol 22:829-835

37. Lewis D, Winner P, Saper J et al (2009) Randomized, doubleblind, placebo-controlled study to evaluate the efficacy and safety of topiramate for migraine prevention in pediatric subjects 12 to 17 years of age. Pediatrics 123:924-934

38. Winner P, Gendolla A, Stayer C et al (2006) Topiramate for migraine prevention in adolescents: a pooled analysis of efficacy and safety. Headache 46:1503-1510

39. Cruz MJ, Valencia I, Legido A et al (2009) Efficacy and tolerability of topiramate in pediatric migraine. Pediatr Neurol 41(3): 167-170

40. Ashrafi MR, Shabanian R, Zamani GR et al (2005) Sodium valproate versus propranolol in paediatric migraine prophylaxis. Eur J Paediatr Neurol 9:333-338

41. Apostol G, Cady RK, Laforet GA, Robieson WZ et al (2008) Divalproex extended-release in adolescent migraine prophylaxis: results of a randomized, double-blind, placebo-controlled study. Headache 48(7):1012-1025

42. Apostol G, Lewis DW, Laforet GA et al (2009) Divalproex sodium extended-release for the prophylaxis of migraine headache in adolescents: results of a stand-alone, long-term open-label safety study. Headache 49(1):45-53

43. Miller GS (2004) Efficacy and safety of levetiracetam in pediatric migraine. Headache 44:238-243

44. Pakalnis A, Kring D, Meier L (2007) Levetiracetam prophylaxis in pediatric migraine-an open-label study. Headache 47(3):427430

45. Pakalnis A, Kring D (2006) Zonisamide prophylaxis in refractory pediatric headache. Headache 46(5):804-807 